Article

\title{
Preparation and Characterization of Diene Rubbers/Silica Composites via Reactions of Hydroxyl Groups and Blocked Polyisocyanates
}

\author{
Lun Ge and Qiang Liu*
}

check for updates

Citation: Ge, L.; Liu, Q. Preparation and Characterization of Diene

Rubbers/Silica Composites via

Reactions of Hydroxyl Groups and Blocked Polyisocyanates. Polymers 2022, 14, 461. https://doi.org/ $10.3390 /$ polym 14030461

Academic Editor: Alexandrina Nan

Received: 5 January 2022

Accepted: 18 January 2022

Published: 24 January 2022

Publisher's Note: MDPI stays neutral with regard to jurisdictional claims in published maps and institutional affiliations.

Copyright: (C) 2022 by the authors. Licensee MDPI, Basel, Switzerland. This article is an open access article distributed under the terms and conditions of the Creative Commons Attribution (CC BY) license (https:// creativecommons.org/licenses/by/ $4.0 /)$.
Key Laboratory of Rubber-Plastics of Ministry of Education, Qingdao University of Science \& Technology, Qingdao 266042, China; 2019020002@mails.qust.edu.cn

* Correspondence: liuqiang@qust.edu.cn

\begin{abstract}
To improve the curing reaction rate and efficiency of sulfur-cured diene-based rubbers, the introduction of some chemical compounds as activators and accelerants is inevitably required, causing potential harm to humans and ecological systems. Moreover, silica is usually employed as a green filling material for rubber reinforcement, and a silane coupling agent is always required to improve its dispersion. Herein, we reported an effective method to cure hydroxyl-functionalized rubbers/silica composites with blocked polyisocyanates, avoiding the use of any other additives. The enhanced dispersion of silica by interaction with hydroxyl groups on molecular chains endowed the composites with high-mechanical performance. The mechanical properties and crosslinking kinetics of the resultant silica composites can be regulated by adjusting the content of hydroxyl groups in the rubber, as well as the amount of the blocked polyisocyanates. The dynamic heat build-up was related to the distance between crosslinking points. A SBROH/B-TDI/silica composite prepared with blocked toluene diisocyanatem (TDI) exhibited comparable tan $\delta\left(0.21\right.$ at $0{ }^{\circ} \mathrm{C}$ and 0.11 at $\left.60{ }^{\circ} \mathrm{C}\right)$ to that of silica composites cured by sulfur with the help of a silane coupling agent (SBR/S/Si69/silica, 0.18 and 0.10 ), suggesting great applicable potential for new tire rubber compounds.
\end{abstract}

Keywords: diene rubber; hydroxyl group; blocked polyisocyanates; crosslinking; silica

\section{Introduction}

Vulcanization involves crosslinking between polymer chains physically or chemically to generate three-dimensional network structures, which play a key role in achieving rubbery elasticity [1,2]. Even though various chemicals, such as peroxides [3], metal peroxides [4], amines [5] and resins [6], have been developed for the vulcanization of rubbers, the sulfur crosslinking system, first reported by Goodyear in 1839, is still most widely used in the industry. Due to the low crosslinking efficiency of using sulfur alone, activators and accelerants must be introduced to facilitate the crosslinking process and optimize the network performance $[7,8]$. However, these additives are usually toxic and will release harmful substances during the curing process [9]. For example, the activator zinc oxide is classified as toxic to aquatic organisms by the European Commission, and its application in rubber technology must be controlled by legislation [10]. Moreover, N-cyclohexyl-2benzothi-azolesulphonamide (accelerant CZ), dibenzothiazoledisulfide (accelerant DM), and 2,2'-dibenzothiazole disulphide (accelerant MBTS) are classified as R43 (may cause sensitization by skin contact) and R50/53 (very toxic to aquatic organisms) according to the dangerous substances directive of European Union laws (67/548/EEC) [11]. Therefore, it is an urgent demand to explore an efficient and green method to crosslink diene rubbers. This leads to many attempts for developing new crosslinking structures, such as a physical crosslinking network formed by hydrogen bonds [12], ionic interaction [13], epoxy-functionalized elastomers crosslinked by dibasic acids [14,15], hydroxylated rubbers 
cured with various acrylates based on the oxa-Michael reaction [16], and diene rubbers crosslinked by the inverse vulcanized co-polymer [17].

In the early 1970s, a type of crosslinking system commonly referred to as urethane crosslinking was reported [18-20]. In this system, urea-urea crosslinks are created via a diisocyanate which is blocked by quione oxime, a tautomer of $p$-nitrosophenol. However, the high cost and poor compression preclude its widespread industrial applications. In 1990, Goodyear developed a crosslink technology based on reactivity rubbers (SBR or NBR) containing active hydrogens or blocked diisocyanates [21]. The resulting urethane crosslinks are remarkably durable under both thermal and hydrolytic conditions with carbon black (CB) as the filling material. However, the tensile strength of the prepared SBR/CB composites were quite low (about 12-18 MPa). In addition, the dynamic heat build-up study for this urethane crosslinking system was not involved.

Nanosilica is widely used as filler for "green tire" rubber matrix in tire industry [22,23], because it can reduce rolling resistance and enhance both mechanical properties and wet skid resistance $[24,25]$. The dispersion of filler is well known for deciding the performance of rubbers [26,27]. It is, however, difficult to disperse in non-polar rubber because there is a large number of silanol groups on the surface of silica [28,29]. A silane coupling agent is confirmed to be capable of improving the dispersion of silica in rubber significantly, but the need of additional high-temperature treatment increases the complexity of processing [30]. It has been very recently demonstrated that intra-chain functional groups in rubber can effectively improve the dispersion of silica through polar interaction or chemical connection [31-33].

Herein, we used a strategy to prepare hydroxyl-functionalized rubbers by epoxidation functionalization of diene rubbers with peroxide and subsequent acid ring opening reactions. Polyisocyanates are then used to crosslink hydroxyl-functionalized rubbers by using silica as a reinforcement material. We found that the hydroxyl groups in the rubber molecular chains can promote the dispersion of silica, thus resulting in high mechanical performance of hydroxyl-functionalized $\mathrm{BR}(\mathrm{BROH}) /$ silica and hydroxyl-functionalized $\mathrm{SBR}(\mathrm{SBROH}) /$ silica composites. In addition, the effect of hydroxyl groups content and chemical structure of blocked polyisocyanates on dynamic heat build-up for this urethane crosslinking system were studied.

\section{Materials and Methods}

\subsection{Materials}

The materials used were as follows: cis-1,4-polybutadiene rubber (BR, trade name: BR 9000, Beijing Yanshan Petrochemical Co. Ltd., Beijing, China); butadiene styrene rubber (SBR, trade name: SBR1502, styrene content of $23.5 \mathrm{wt} \%$, Qilu Petrochemical Co. Ltd., Shandong, China); tetrahydrofuran (THF, Sinopharm Chemical Reagent Co. Ltd. Shanghai, China), 3-Chloroperbenzoic acid (mCPBA, 85\%, Saan Chemical Technology Co. Ltd. Shanghai, China); hydrochloric acid ( $\mathrm{HCl}, 38 \mathrm{wt} \%$ aqueous solution, Sinopharm Chemical Reagent Co. Ltd., Shanghai, China); hexamethylene diisocyanate, 1,4-Phenylene diisocyanate, and tolylene-2,4-diisocyanate (HDI, PPDI, TDI, Saan Chemical Technology Co. Ltd. Shanghai, China); butanone oxime (Saan Chemical Technology Co. Ltd. Shanghai, China); precipitated silica (trade name VN3, Evonik Degussa Co. Ltd. Shanghai, China); and blocked polyisocyanate (trade name VESTANAT B1358/100, referred to as BI, Evonik Degussa Co. Ltd. Shanghai, China). Other rubber additives were industrially available and used as received without further purification.

\subsubsection{Preparation of Hydroxylated BR and Hydroxylated SBR}

Pendant hydroxyl group functionalized BR $\left(\mathrm{BROH}_{\mathrm{x}}\right)$ and SBR $\left(\mathrm{SBROH}_{\mathrm{x}}\right)$ were synthesized according to the literature procedure [34]. Take $\mathrm{BROH}_{3}$ (containing $3 \mathrm{~mol} \%$ hydroxyl groups) as an example; in a three-necked flask, $50 \mathrm{~g}$ of $\mathrm{BR}(0.926 \mathrm{~mol} \mathrm{C}=\mathrm{C})$ were well dissolved in THF $(0.05 \mathrm{~g} / \mathrm{mL})$. A solution of $5.68 \mathrm{~g}$ of mCPBA $(0.028 \mathrm{~mol})$ in $50 \mathrm{~mL}$ of THF was then added dropwise at room temperature $\left(25^{\circ} \mathrm{C}\right)$ into the polymer solution at such a 
rate that the mCPBA solution was added completely after $1 \mathrm{~h}$. The reaction mixture was then further stirred for another $2 \mathrm{~h}$. A solution of $4.7 \mathrm{~mL}$ of hydrochloric acid $(0.056 \mathrm{~mol}$ of $\mathrm{HCl}$ ) in $50 \mathrm{~mL}$ of THF was first prepared and transferred into a $100 \mathrm{~mL}$ dropping funnel; it was then added dropwise at room temperature $\left(25^{\circ} \mathrm{C}\right)$ into the epoxidized BR solution prepared previously. After the addition of the $\mathrm{HCl}$ solution, the reaction mixture was further stirred for another $2 \mathrm{~h}$ to complete the ring-opening reaction. The resultant solution was poured into $\mathrm{H}_{2} \mathrm{O}$ under stirring to precipitate the modified $\mathrm{BR}$. The product was further dissolved in THF and precipitated by $\mathrm{H}_{2} \mathrm{O}$ repeatedly to fully remove the unreacted agents. Subsequently, the resulting polymer was dried in a vacuum oven at $40{ }^{\circ} \mathrm{C}$ to remove the residual solvent. The hydroxylated $\mathrm{BR}$ is denominated as $\mathrm{BROH}_{\mathrm{x}}$, where $\mathrm{x}$ represents the molar percentage of the hydroxyl group. To investigate the effect of hydroxyl group content on cured rubber performance, BR with different contents of hydroxyl groups was synthesized according to the abovementioned procedures. Besides $3.0 \mathrm{~mol} \%$, other hydroxyl group contents were controlled to be 1.0 and $5.0 \mathrm{~mol} \%$. Additionally, SBR with different contents of hydroxyl groups (2.0, 5.0, and $7.0 \mathrm{~mol} \%$ ) were synthesized.

\subsubsection{Preparation of Blocked Polyisocyanates}

In a three-port bottle equipped with magnetic stirring and a condensation tube and protected by dry nitrogen gas, $8.7 \mathrm{~g}$ TDI $(0.05 \mathrm{~mol}), 10.4 \mathrm{~g}$ butanone oxime $(0.12 \mathrm{~mol})$, and $20 \mathrm{~mL}$ ethyl acetate were added, This mixture was reacted for $5 \mathrm{~h}$ at $77^{\circ} \mathrm{C}$ and then distilled under reduced pressure to remove ethyl acetate. The resulting product was dried in a vacuum oven at $40^{\circ} \mathrm{C}$ to remove the residual solvent. Blocked hexamethylene diisocyanate (BHDI); blocked 1,4-Phenylene diisocyanate (BPPDI); and blocked tolylene-2,4diisocyanate (BTDI) were separately synthesized using butanone oxime as a blocking agent.

\subsubsection{Preparation of $\mathrm{BROH}_{\mathrm{x}} / \mathrm{BI} /$ Silica and $\mathrm{BR} / \mathrm{S} /$ Silica Composites}

For the preparation of $\mathrm{BROH}_{\mathrm{x}} / \mathrm{BI} /$ silica, $100 \mathrm{~g}$ of $\mathrm{BROH}_{\mathrm{x}}, 30 \mathrm{~g}$ of silica, and various amounts of $\mathrm{BI}(4,6,8 \mathrm{~g})$ were mixed in a Haake internal mixer. The obtained compounds were then subjected to compression moulding at $160{ }^{\circ} \mathrm{C}$ for optimum time to produce $\mathrm{BI}$-cured $\mathrm{BROH}_{\mathrm{x}}$. The formed product was named $\mathrm{BROH}_{\mathrm{x}} \mathrm{BI}_{\mathrm{z}}$, where $\mathrm{z}$ is the content (phr, parts per hundreds of rubbers) of the crosslinker. Traditional sulfur-cured BR (BR/S) was prepared according to the abovementioned protocols based on the below formulation: BR 100 g; silica $30 \mathrm{~g}$; bis[ $\gamma$-(triethoxysilyl)propyl]tetrasulfide (Si69) 0 or 2.4 g; zinc oxide $5.0 \mathrm{~g}$; stearic acid $1.0 \mathrm{~g}$; N-Isopropyl-N'-phenyl-4-phenylenediamin (4010NA) $1.0 \mathrm{~g}$; 1,3-Diphenylguanidine (D) $0.5 \mathrm{~g}$; N-cyclohexyl-2-benzothiazole sulphonamide (CZ) $1.5 \mathrm{~g}$; and sulfur $1.5 \mathrm{~g}$.

\subsubsection{Preparation of $\mathrm{SBROH}_{\mathrm{x}} / \mathrm{BI} /$ Silica and SBR/S/Silica Composites}

For the preparation of $\mathrm{SBROH}_{\mathrm{x}} / \mathrm{BI} /$ silica, $100 \mathrm{~g}$ of $\mathrm{SBROH}_{\mathrm{x}} ; 50 \mathrm{~g}$ of silica; and blocked polyisocyanates (6 g BI, $3.06 \mathrm{~g}$ BHDI, $2.99 \mathrm{~g}$ BPPDI and $3.11 \mathrm{~g}$ BTDI, respectively) were mixed in a Haake internal mixer. The obtained compounds were then subjected to compression moulding at $160^{\circ} \mathrm{C}$ for optimum time to produce $\mathrm{BI}$-cured $\mathrm{SBROH}_{\mathrm{x}}$. The formed product was named $\mathrm{SBROH}_{\mathrm{x}} \mathrm{BI}_{\mathrm{z}}$, where $\mathrm{z}$ is the content (phr, parts per hundreds of rubbers) of the crosslinker. Traditional sulfur-cured SBR (SBR/S) was prepared according to the abovementioned protocols based on the below formulation: SBR $100 \mathrm{~g}$; silica $50 \mathrm{~g}$; bis[ $\gamma$-(triethoxysilyl)propyl]tetrasulfide (Si69) 0 or $5 \mathrm{~g}$; zinc oxide $3.0 \mathrm{~g}$; stearic acid $2.0 \mathrm{~g}$; N-Isopropyl-N'-phenyl-4-phenylenediamin (4010NA) 1.0 g; N-tert-butylbenzothiazole-2sulphenamide (NS) $2 \mathrm{~g}$; and sulfur $1.5 \mathrm{~g}$.

\subsection{Methods}

The ${ }^{1} \mathrm{H}$ NMR spectra of products were recorded using a Bruker 500 spectrometer with $\mathrm{CDCl}_{3}$ as a solvent and tetramethylsilane (TMS) as an internal standard. A Fouriertransform infrared spectroscopy (FTIR) analysis was conducted on a VERTEX 70 instrument in attenuated total reflectance (ATR) mode. The spectra were collected over the wavenum- 
ber of $4000-500 \mathrm{~cm}^{-1}$ with a $4 \mathrm{~cm}^{-1}$ resolution and 32 scans. The molecular weight $\left(M_{\mathrm{n}}\right)$ and molecular weight distribution (PDI, $M_{\mathrm{w}} / M_{\mathrm{n}}$ ) of the polymers were measured by GPC equipped with an RI detector (GPC-RI) and an EcoSEC832 pump. The flow rate of tetrahydrofuran (THF) was $0.35 \mathrm{~mL} / \mathrm{min}$. Differential scanning calorimetry (DSC) was recorded on a DSC204F1 instrument (NETZSCH) and thermograms were recorded using a heating rate of $10^{\circ} \mathrm{C} / \mathrm{min}$ under nitrogen atmosphere from $-80^{\circ} \mathrm{C}$ to $40^{\circ} \mathrm{C}$. Crosslinking kinetics were determined at different temperatures on an MDR2000 (Alpha Technologies, Wilmington, DE, USA) vulcameter. The tensile and tear test was carried out by a Zwick/Roell Z005 instrument. Shore A hardness was performed on a durometer (GOTECH Testing Machines Company). Resilience was performed on a rubber rebound testing machine (GOTECH Testing Machines Company). Compression set retention rate was performed on a rubber compression permanent deformer at $25 \%$ compression for $72 \mathrm{~h}$ at room temperature. Crosslinking density was measured by the equilibrium swelling experiment (see Supporting Information). Dynamic mechanical analysis (DMA) was performed using a NETZSCH EPlexor $500 \mathrm{~N}$ analyzer under the conditions of a frequency of $10 \mathrm{~Hz}$ at the speed of $3{ }^{\circ} \mathrm{C} / \mathrm{min}$ from $-120{ }^{\circ} \mathrm{C}$ to $80^{\circ} \mathrm{C}$. Filler networks were analyzed using an RPA 2000 at $60^{\circ} \mathrm{C}$ (Alpha Technologies, Wilmington, DE, USA). The compounds were analyzed over the strain range of $0.28-400 \%$ at $1 \mathrm{~Hz}$. Transmission electron microscopy (TEM) for the ultramicrotomed samples was performed on a JEM-2100 instrument (Tokyo, Japan).

\section{Results}

\subsection{Hydroxyl Functionalization of Butadiene Rubber}

A series of pendant hydroxyl-group-functionalized cis-polybutadiene rubber (denominated as $\mathrm{BROH}_{\mathrm{x}}$, where $\mathrm{x}$ represents the molar ratio of structural units containing hydroxyl groups) were synthesized according to Scheme 1 . The commercial blocked polyisocyanates, i.e., B1358 (a closed ring aliphatic polyisocyanate that is based on the isophorone diisocyanate), referred to as BI, was used to cure the silica-filled hydroxyl functionalized rubbers. The formed product was named $\mathrm{BROH}_{\mathrm{x}} \mathrm{BI}_{\mathrm{z}}$, where $\mathrm{z}$ is the content (phr, parts per hundreds of rubbers) of the crosslinker.

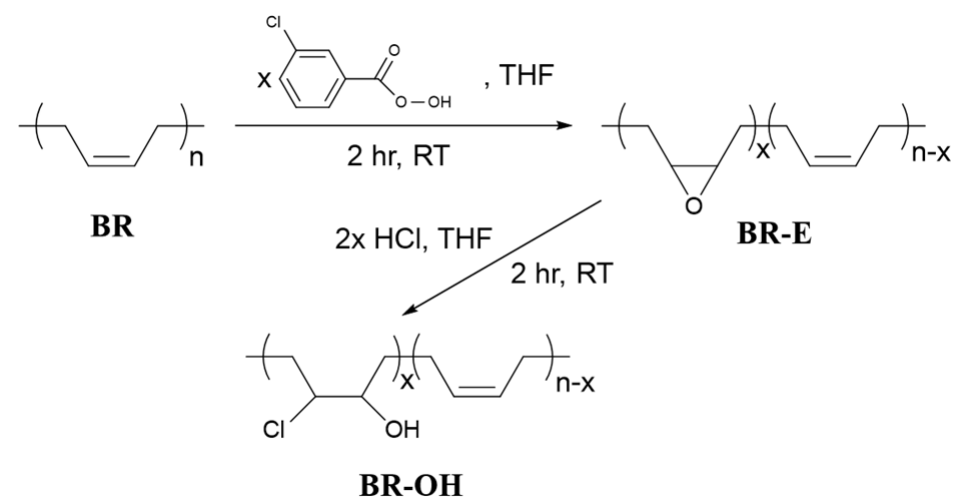

Scheme 1. Preparation of hydroxyl-functionalized rubbers.

The chemical structures of formed products were investigated by FTIR spectra (Figure S1). The peak transmittance intensity was normalized to the peak at around $3008 \mathrm{~cm}^{-1}$ ascribed to $\mathrm{C}-\mathrm{H}$ bending vibration and used to compare the changes of each moiety. The intensity of peaks around $3575 \mathrm{~cm}^{-1}$ corresponding to the $\mathrm{O}-\mathrm{H}$ bending increased continuously while the peak intensity of around $2939 \mathrm{~cm}^{-1}$ representing $=\mathrm{C}-\mathrm{H}$ weakened with the increasing amount of $m$-chloroperoxybenzoic acid (mCPBA) and hydrochloric acid, indicating that the hydroxyl group content increased in the polybutadiene rubber (BR). The hydroxyl group contents were quantitatively determined by ${ }^{1} \mathrm{H}$ NMR spectra as listed in Table S1. The peak at $2.74 \mathrm{ppm}$ (Figure 1) assigned to epoxide groups, which was formed by the epoxidation of mCPBA, completely disappeared after the ring opening reaction in the presence of hydrochloric acid. The double peaks at 3.73 and $3.96 \mathrm{ppm}$ corresponding to hydroxyl 
and chlorine groups were used to calculate the efficiency of ring opening reactions with epoxide and chlorine, respectively [34]. As shown in Table S1, both efficiencies were very high. The molecular weight $\left(M_{W}\right)$ and molecular weight distribution (MWD) of $\mathrm{BROH}_{\mathrm{x}}$ before and after hydroxylation were determined by GPC (Figure S2 and Table S2). The $M_{\mathrm{W}}$ slightly increased as the content of hydroxyl groups increased, indicating the successful grafting of hydroxyl groups onto BR chains.

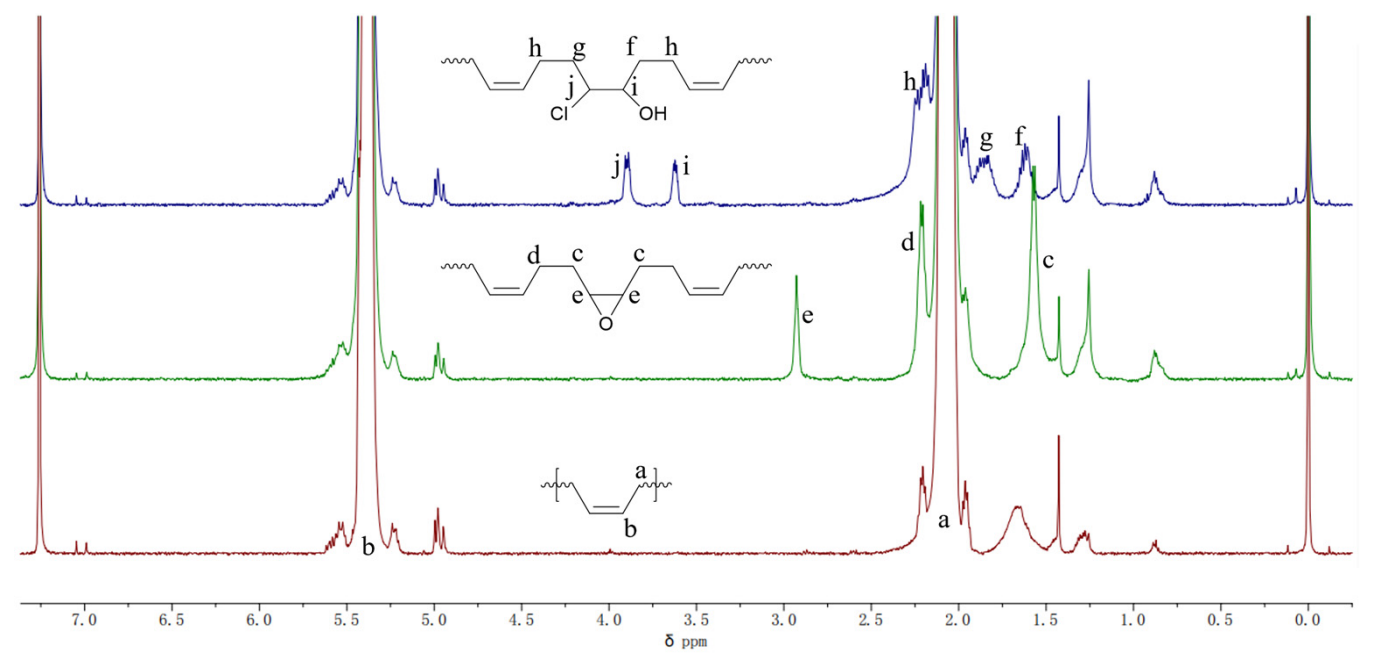

Figure 1. ${ }^{1} \mathrm{H}$ NMR spectra of BR with a $3 \mathrm{~mol} \%$ degree of modification.

\subsection{Crosslinking of $B R O H_{x}$ with Blocked Polyisocyanates}

To explore the reaction mechanism between $\mathrm{BROH}_{\mathrm{x}}$ and blocked polyisocyanates, we monitored the FTIR spectra of $\mathrm{BI}, \mathrm{BROH}_{3}$, and $\mathrm{BROH}_{3} / \mathrm{BI}_{6}$ compounds and $\mathrm{BROH}_{3} / \mathrm{BI}_{6}$ vulcanizate. As seen from Figure $2 \mathrm{a}$, the intensity of peaks at $1739 \mathrm{~cm}^{-1}$ related to $\mathrm{C}=\mathrm{O}$ stretching vibration in blocked polyisocyanates decreases after crosslinking, indicating the successful unblocking of blocked polyisocyanates [35]. Upon the addition of silica, the degree of association of hydroxyl groups increases, leading to peak broadening and red shift to a lower wavenumber. The decreased intensity of peaks at $3440 \mathrm{~cm}^{-1}$ assigned to hydroxyl groups after the curing process confirms clearly the partial consumption of hydroxyl groups in $\mathrm{BROH}_{3}$ by unblocked isocyanate groups. The curing behavior of the $\mathrm{BROH}_{3} / \mathrm{BI} /$ silica composite was examined to verify the effectiveness of crosslinking reactions. Figure $2 \mathrm{~b}$ showed the curing profiles of $\mathrm{BROH}_{3} / \mathrm{BI} /$ silica at different temperatures. At temperatures above the unblocking temperature $\left(130^{\circ} \mathrm{C}\right)$ of $\mathrm{BI}$, the curing process was accelerated as the curing temperature increased, and the maximum torques $(\mathrm{MH})$ were nearly the same, indicating the completion of crosslinking reactions between newly released highly active isocyanate groups and hydroxyl groups. Additionally, the curing curve began to level off after $15 \mathrm{~min}$ at temperatures higher than $150{ }^{\circ} \mathrm{C}$, similar to traditional sulphur-based curing systems. However, at temperatures below the unblocking temperature, the crosslinking reaction was rather slow since the reaction can only rely on a trace amount of free isocyanate groups. For the same reason, the low temperature blending process did not cause early crosslinking and can ensure the processing safely. The crosslinking chemistry based on $\mathrm{BROH}_{\mathrm{x}}$ and blocked polyisocyanates was summarized in Scheme 2 . 

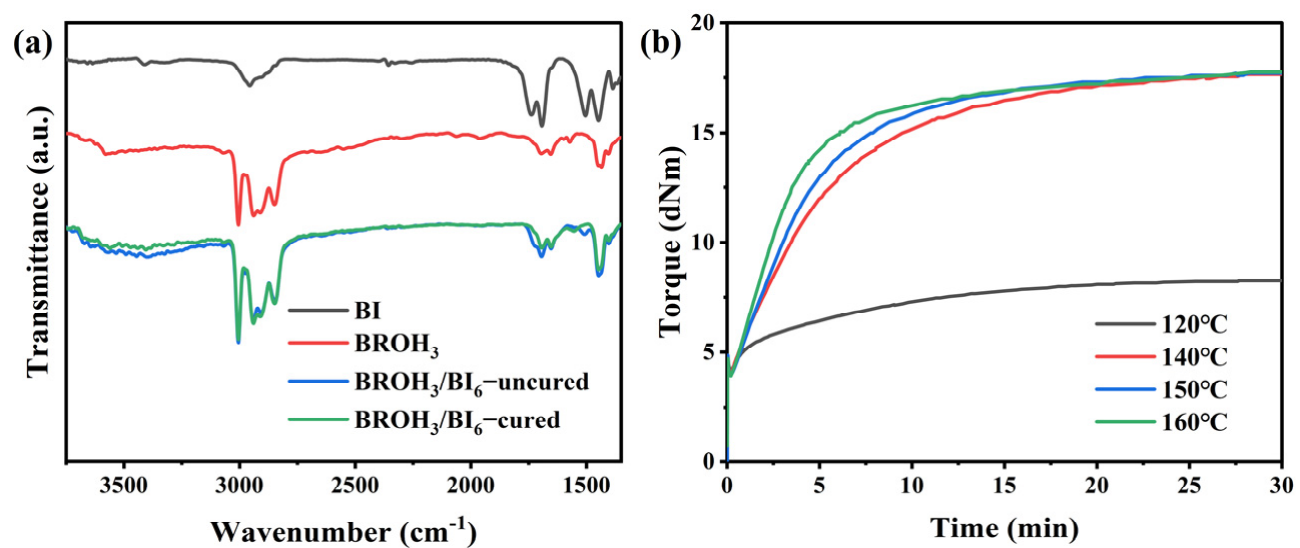

Figure 2. (a) FTIR spectra of $\mathrm{BI}, \mathrm{BROH}_{3}$, and $\mathrm{BROH}_{3} / \mathrm{BI}$ compounds and $\mathrm{BROH}_{3} / \mathrm{BI}_{6}$ vulcanizate and (b) curing profiles of $\mathrm{BROH}_{3} / \mathrm{BI} /$ silica composites at different curing temperatures.<smiles></smiles>

Blocked polyisocyanates

Polyisocyanates

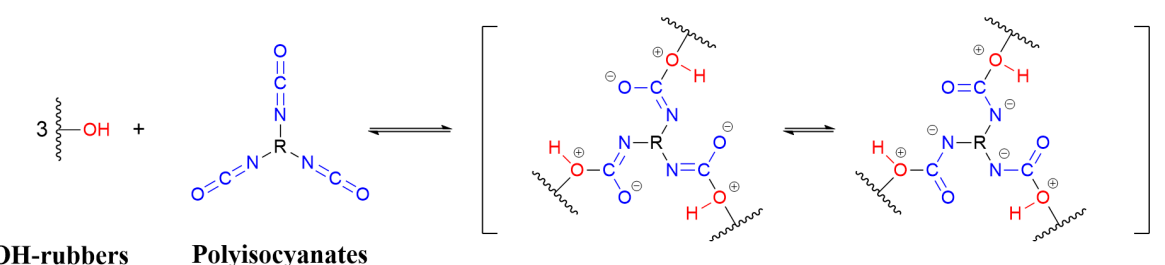

OH-rubbers Polyisocyanates

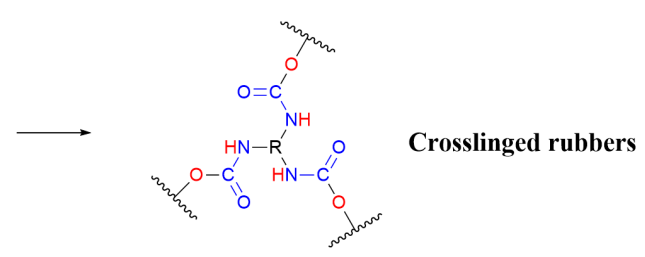

Scheme 2. The unblocking of blocked polyisocyanates and the vulcanization mechanism of polyisocyanates-cured $\mathrm{BROH}_{\mathrm{x}} / \mathrm{BI} /$ silica composite.

\subsection{Mechanical Properties of $\mathrm{BROH}_{x} / \mathrm{BI} /$ Silica Composites}

The mechanical properties of formed rubber composites can be manipulated by adjusting the BI content. Figure 3a was the crosslinking density plot of $\mathrm{BROH}_{\mathrm{x}} / \mathrm{BI} /$ silica composite vs. BI amount. The crosslinking density increased gradually with the increase in $\mathrm{BI}$ amount due to the increase in reaction points. With the increase in BI dosage from 4 to $8 \mathrm{phr}$, the crosslinking density enhanced from 6.63 to $8 \times 10^{-5} \mathrm{~mol} / \mathrm{cm}^{3}$. Figure $3 \mathrm{~b}$ presents the curing curves of $\mathrm{BROH}_{3}$ using different $\mathrm{BI}$ doses. With the increase in BI content, the crosslinking density and $\mathrm{MH}$ value increased monotonously. Moreover, the crosslinker content had little effect on the curing time. The stress-strain curves of $\mathrm{BROH}_{\mathrm{x}} / \mathrm{BI} /$ silica composites areshown in Figure 3c. With the increase in BI amount, the tensile strength and modulus of $\mathrm{BROH}_{\mathrm{x}} / \mathrm{BI} /$ silica composites increased obviously, and the breaking elongation decreased because of increasing crosslinking density. 

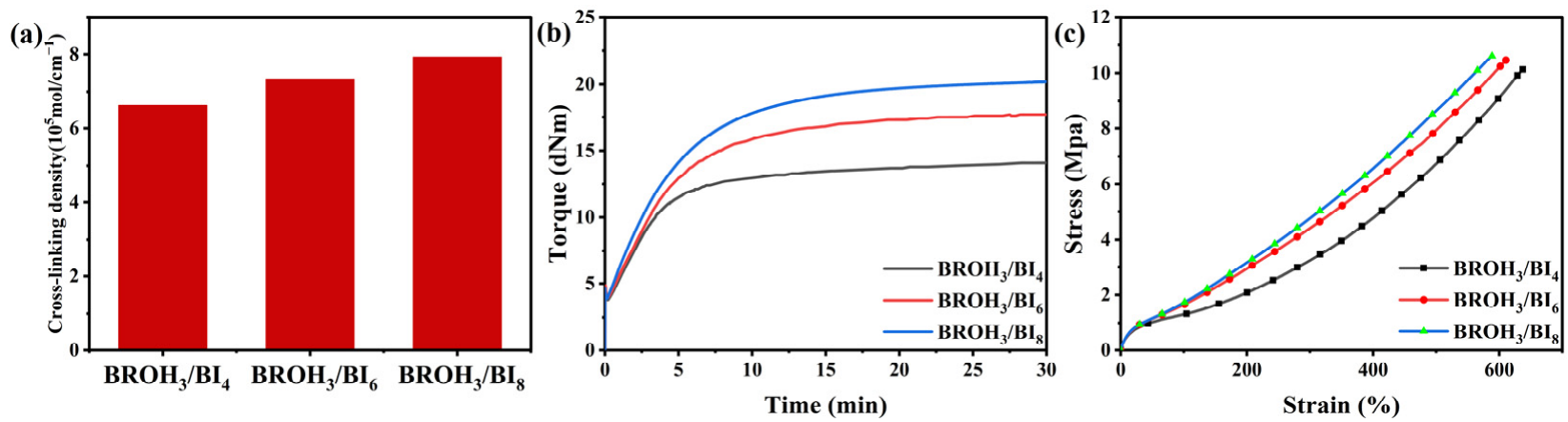

Figure 3. (a) crosslink density, (b) curing curves, and (c) stress-strain curves of $\mathrm{BROH}_{3}$ cured by different amounts of BI.

The effect of hydroxyl group content on the performance of cured rubber was further investigated. As shown in Figure 4a, at a constant dosage of BI (6 phr), the crosslinking density of $\mathrm{BROH}_{\mathrm{x}}$ increased with the increasing hydroxyl group content because of increasing amount of curing sites. The crosslinking density exhibited an abrupt increase from 4.46 to $7.34 \times 10^{-5} \mathrm{~mol} / \mathrm{cm}^{3}$ when the hydroxyl group content increased from 1 to $3 \mathrm{~mol} \%$. In contrast, a further increase in the hydroxyl content from 3 to $5 \mathrm{~mol} \%$, only led to a slight increase in crosslinking density. The possible reason was that effective crosslinking can only be realized when at least two of the three isocyanate groups in each BI react with the rubber chains. When the $\mathrm{BROH}_{\mathrm{x}}$ hydroxyl content was low (e.g., $\mathrm{BROH}_{1}$ ), no effective crosslinking could be formed because of the reduced possibility of the limited hydroxyl groups to react with multiple isocyanate groups in each BI. At a higher content of hydroxyl groups (e.g., $\mathrm{BROH}_{5}$ ), more hydroxyl groups were accessible to isocyanate groups of $\mathrm{BI}$ for effective crosslinking. Figure $4 \mathrm{~b}$ depicts the curing curves of $\mathrm{BROH}_{\mathrm{x}} / \mathrm{BI} /$ silica composites with the hydroxyl group contents. High hydroxyl group content led to a shortened curing time and an increased $\mathrm{MH}$ due to a higher crosslinking density. The stress-strain curves of $\mathrm{BROH}_{\mathrm{x}} / \mathrm{BI} /$ silica composites are shown in Figure 4c. Both the tensile strength and modulus were enhanced with the increase in hydroxyl group content. The elongation at break depended also remarkably on the hydroxyl content, which was attributed to the increment of the crosslinking density, as well.
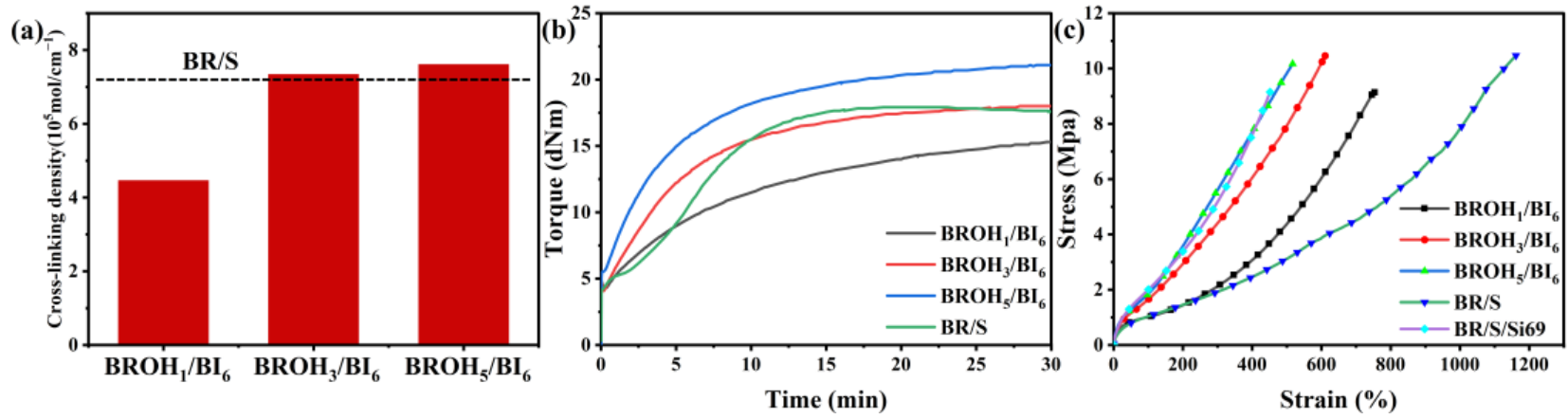

Figure 4. (a) crosslink density, (b) curing curves, and (c) stress-strain curves of $\mathrm{BROH}_{\mathrm{x}}$ cured by 6 phr BI.

Notably, the modulus of the $\mathrm{BROH}_{3} / \mathrm{BI}_{6}$ / silica composite was as high as $4.4 \mathrm{MPa}$ at a strain of $300 \%$, close to the value of the BR silica composite with Si69 added (Table 1, BR/S/Si69/silica), much higher than those of BR composites with similar crosslinking density prepared using the traditional sulphur-cured BR/S/silica composite (Figure 4a, $\mathrm{BR} / \mathrm{S} /$ silica). Additionally, the resilience and the permanent deformation retention in compression were all enhanced with the increase in hydroxyl content. The tensile strength and modulus of $\mathrm{BROH}_{5} / \mathrm{BI}_{6}$ were even superior to the traditional $\mathrm{BR} / \mathrm{S} / \mathrm{Si} 69 /$ silica composite, but the values of permanent set, resilience, and compression set were higher than that of the BR/S/Si69 composite at different hydroxyl contents. 
Table 1. Mechanical properties of $\mathrm{BROH} / \mathrm{BI} /$ silica composites.

\begin{tabular}{ccccccccc}
\hline Sample & $\begin{array}{c}\text { Tensile } \\
\text { Strength } \\
\mathbf{( M P a )}\end{array}$ & $\begin{array}{c}\text { Modulus } \\
\text { at 100\% } \\
\mathbf{( M P a )}\end{array}$ & $\begin{array}{c}\text { Modulus } \\
\text { at 300\% } \\
\mathbf{( M P a )}\end{array}$ & $\begin{array}{c}\text { Elongation } \\
\text { at Break (\%) }\end{array}$ & $\begin{array}{c}\text { Shore A } \\
\text { Hardness }\end{array}$ & $\begin{array}{c}\text { Permanent } \\
\text { Set (\%) }\end{array}$ & $\begin{array}{c}\text { Resilience } \\
\mathbf{( \% )}\end{array}$ & $\begin{array}{c}\text { Compression } \\
\text { Set (\%) }\end{array}$ \\
\hline $\mathrm{BR} / \mathrm{S}$ & 10.4 & 1.0 & 1.9 & 1101 & 60 & 24 & 62.8 \\
$\mathrm{BR} / \mathrm{S} / \mathrm{Si} 69$ & 9.1 & 1.9 & 5.1 & 451 & 66 & 5 & 79.4 & 6.4 \\
$\mathrm{BROH}$ & $/ \mathrm{BI}_{6}$ & 9.1 & 1.0 & 2.1 & 754 & 58 & 22 & 61.4 \\
$\mathrm{BROH}_{3} / \mathrm{BI}_{6}$ & 10.5 & 1.7 & 4.4 & 610 & 60 & 16 & 64.3 \\
$\mathrm{BROH}_{5} / \mathrm{BI}_{6}$ & 10.1 & 1.9 & 5.6 & 517 & 63 & 12 & 68.8 \\
\hline
\end{tabular}

\subsection{Mechanical Properties of $S B R O H_{x} / B I / S i l i c a$ Composites}

It should be noted that this BI-cured system was generally applicable to other dienebased rubbers, such as styrene butadiene rubber (SBR). A series of pendant hydroxylgroup-functionalized SBR (denominated as $\mathrm{SBROH}_{\mathrm{x}}, \mathrm{FTIR},{ }^{1} \mathrm{H}$ NMR, and GPC, which are shown in Figures S3 and S4 and Table S3) were synthesized in the same way. Additionally, the effect of hydroxyl content on glass transition temperature $\left(T_{\mathrm{g}}\right)$ was characterized by a DSC test. As shown in Figure 5, with the increase in content of hydroxyl groups, $T_{\mathrm{g}}$ gradually increased from -52 to $-35.1^{\circ} \mathrm{C}$, which may be attributed to the enhancement of chain polarity and hydrogen bonding interactions. There were some changes in the DSC curve of SBR at about -20 and $10^{\circ} \mathrm{C}$. It is proposed that these changes may be attributed to some unknown thermodynamic transformations originating from the impurities and additives in commercial SBR.

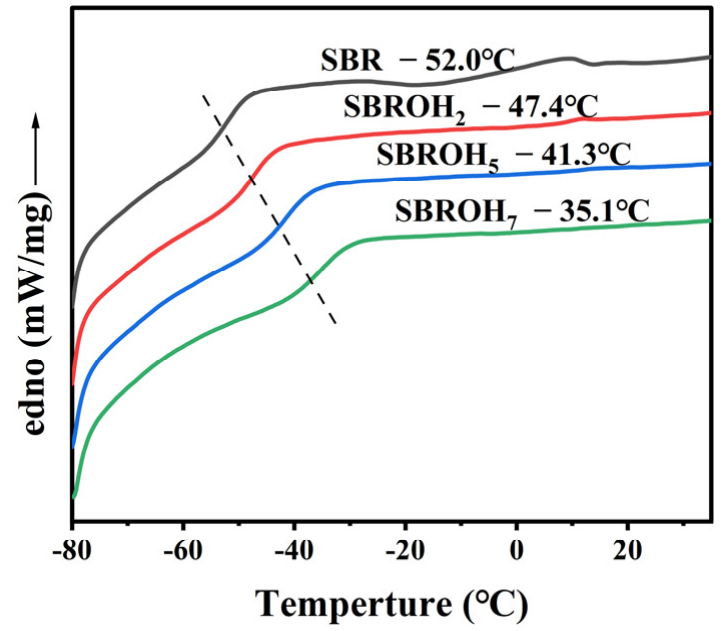

Figure 5. DSC curves of $\mathrm{SBROH}_{\mathrm{x}}$.

The effect of hydroxyl content on the properties of $\mathrm{SBROH}_{x} / \mathrm{BI} /$ silica composites was investigated with a fixed dosage (6 phr) of BI. As shown in Figure 6, as with BROHx/BI/Silica composites, the crosslinking density increased with the increase in hydroxyl content. The $\mathrm{MH}$ also increased with the increase in crosslinking density. As shown in Figure 6c, the elongation at break of $\mathrm{SBROH}_{2}$ was close to that of the SBR/S/silica composite (cured by sulfur), while the modulus and tensile strength were higher. The modulus for $\mathrm{SBROH}_{\mathrm{x}}$ can be further improved close to or even higher than that of the SBR/S/Si69/silica composite (cured by sulfur with the help of Si69). However, the elongation at break would be decreased with contents of hydroxyl groups (see Table 2). 
(a)

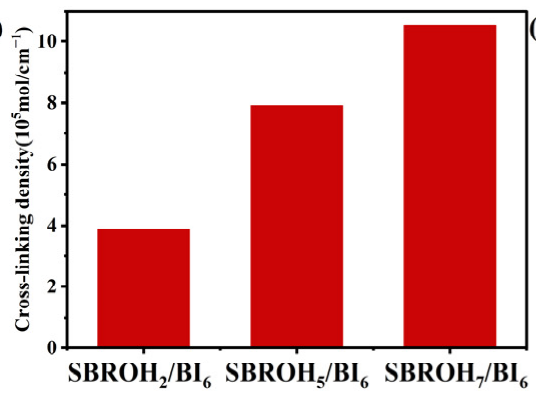

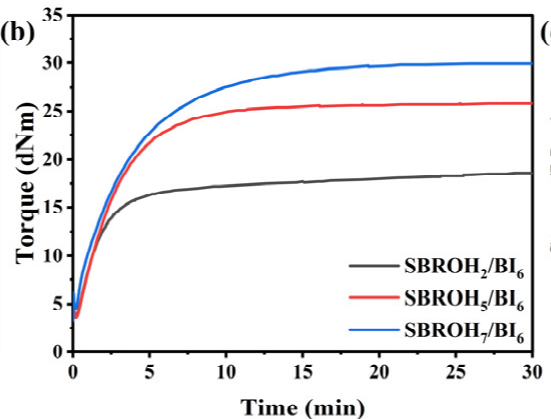

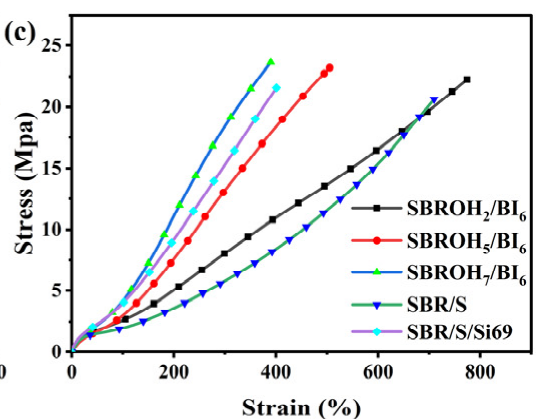

Figure 6. (a) crosslink density, (b) curing curves, and (c) stress-strain curves of $\mathrm{SBROH}_{\mathrm{x}}$ cured by $6 \mathrm{phr} \mathrm{BI}$.

Table 2. Mechanical properties of SBROH/BI/silica composites.

\begin{tabular}{ccccccccc}
\hline Sample & $\begin{array}{c}\text { Tensile } \\
\text { Strength } \\
\mathbf{( M P a )}\end{array}$ & $\begin{array}{c}\text { Modulus } \\
\text { at 100\% } \\
\mathbf{( M P a )}\end{array}$ & $\begin{array}{c}\text { Modulus } \\
\text { at 300\% } \\
\mathbf{( M P a )}\end{array}$ & $\begin{array}{c}\text { Elongation } \\
\text { at Break (\%) }\end{array}$ & $\begin{array}{c}\text { Shore A } \\
\text { Hardness }\end{array}$ & $\begin{array}{c}\text { Permanent } \\
\text { Set (\%) }\end{array}$ & $\begin{array}{c}\text { Resilience } \\
(\%)\end{array}$ & $\begin{array}{c}\text { Compression } \\
\text { Set (\%) }\end{array}$ \\
\hline $\mathrm{SBR} / \mathrm{S}$ & 20.8 & 2.0 & 5.8 & 709 & 70 & 30 & 44.6 & 21.3 \\
$\mathrm{SBR} / \mathrm{S} / \mathrm{Si} 69$ & 21.6 & 4.0 & 15.3 & 401 & 76 & 9 & 51.4 & 11.1 \\
$\mathrm{SBROH}_{2} / \mathrm{BI}_{6}$ & 22.2 & 2.6 & 8.0 & 774 & 72 & 22 & 42.6 & 29.8 \\
$\mathrm{SBROH}_{5} / \mathrm{BI}_{6}$ & 23.2 & 3.0 & 13.2 & 505 & 76 & 15 & 44.2 & 23.1 \\
$\mathrm{SBROH}_{7} / \mathrm{BI}_{6}$ & 23.6 & 4.22 & 18.5 & 389 & 80 & 10 & 47.3 & 20.2 \\
\hline
\end{tabular}

\subsection{Dispersion of Silica in the Rubber Matrix}

We recall that the dispersion of filler is key for deciding the performance of rubber [26,27]. It was found that the introduction of hydroxyl groups facilitates the dispersion of silica (TEM image Figure $7 \mathrm{~b}$ ) because of the enhanced interaction of rubber chains with silica. An RPA analysis was performed on rubbers before and after hydroxylation treatment. As shown in Figure 7a, typical Payne effects were observed for SBR/S/silica composites: the initial very high modulus decreases rapidly with the increase in strain [36]. In contrast, the SBROH/BI/silica composites exhibited a much lower initial storage modulus, and the Payne effects were weaker with higher hydroxyl contents, even equivalent to that of te SBR/S/Si69/Silica composite at a hydroxyl content of $7 \mathrm{~mol} \%$, suggesting a good dispersion of silica. Similarly, Payne effects with BROH/BI/Silica composites (Figure S5) were weakened significantly with the increasing content of hydroxyl groups.

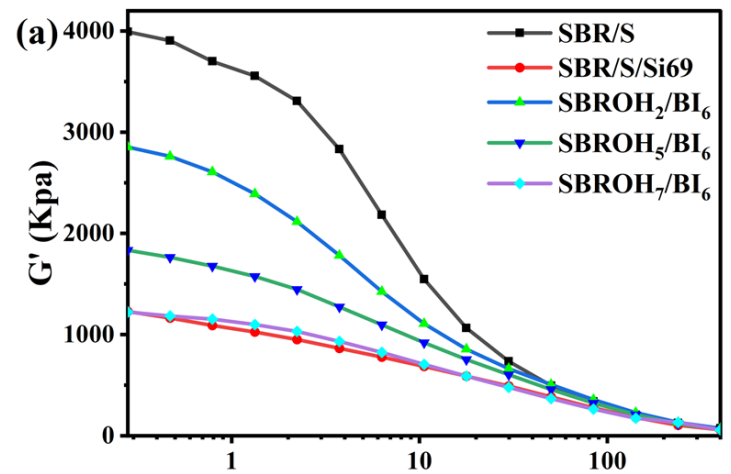

(b)

Strain $(\%)$

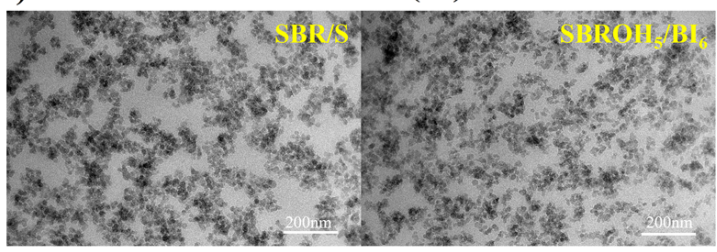

Figure 7. (a) RPA analysis, (b) TEM images of SBR/silica and SBROH/silica composites. 


\subsection{Dynamic Mechanical Properties of $\mathrm{SBROH}_{5} /$ Silica Composites Cured with Different Polyisocyanates}

A trade-off was the decrease in resilience and the permanent deformation retention in compression for $\mathrm{BROH} / \mathrm{BI} /$ silica composites and SBROH/BI/silica composites (see Tables 1 and 2). The effect of hydroxyl groups content on the dynamic behavior of the $\mathrm{SBROH} / \mathrm{BI} /$ silica composites is shown in Figure 8. The $T_{\mathrm{g}}$ increased with the increase in hydroxyl groups content, coherent with the observation in DSC tests. However, compared to the SBR/S/Si69/silica composite, the tan $\delta$ at $60^{\circ} \mathrm{C}$ for SBROH/BI/silica composites were all clearly higher, which is possibly because of a bigger inter crosslink distance. Although some damping materials required higher $\tan \delta$, low $\tan \delta$ and dynamic heat build-up is more desirable for more applications, such as tread compound. Therefore, the effect of the isocyanate structure was further studied by varying the distance between crosslinking points.

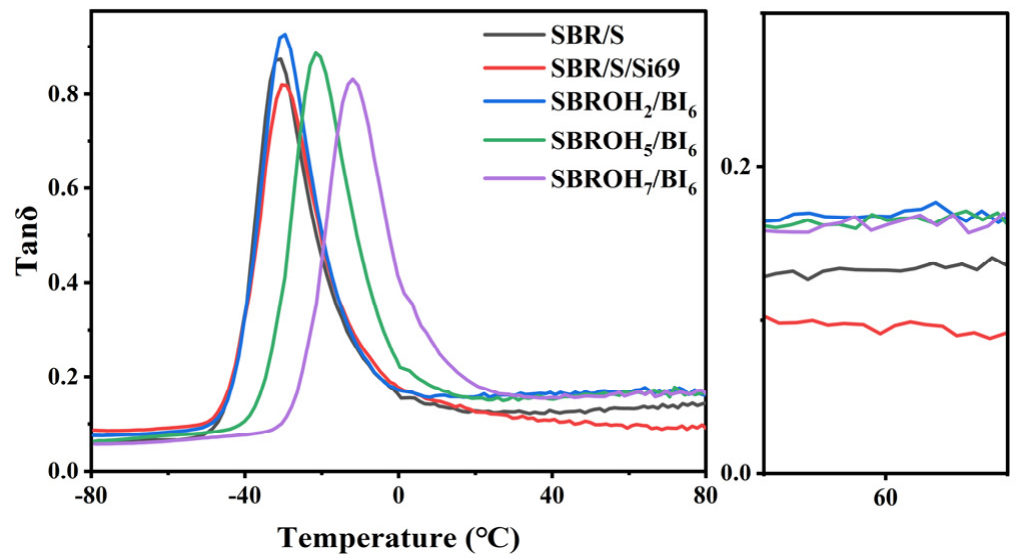

Figure 8. Tan $\delta$-T curves of SBR/S/silica, SBR/S/Si69/silica, and $\mathrm{SBROH}_{\mathrm{x}} /$ silica composites.

Blocked hexamethylene diisocyanate (B-HDI); 1,4-Phenylene diisocyanate (B-PPDI); and toluene-2,4-diisocyanate (B-TDI) were synthesized (Scheme 3) using butanone oxime. The distance between the two NCO groups for these three diisocyanates increased sequentially. The blocking reaction was complete, as the peak at $2270 \mathrm{~cm}^{-1}$ assigned to NCO groups in TDI disappeared after the reaction (FTIR spectra, Figure S6).

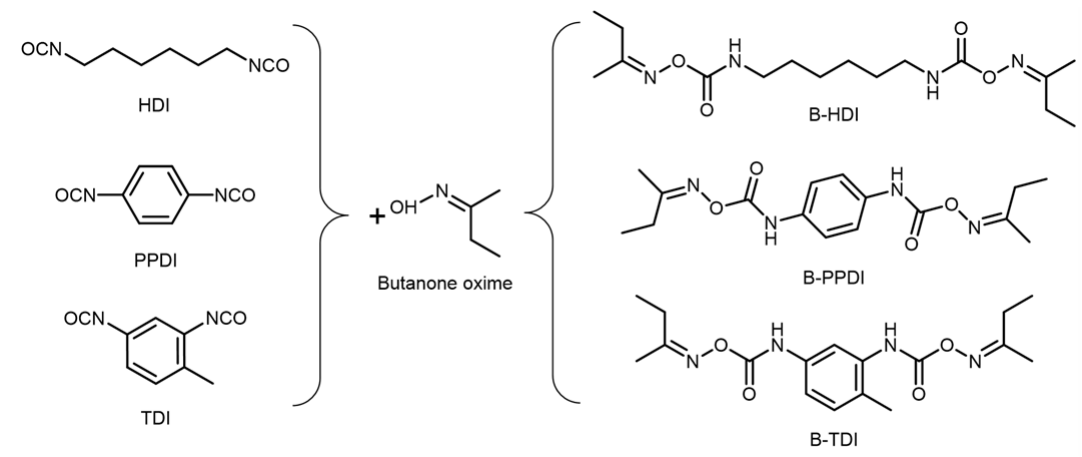

Scheme 3. Preparation of different blocked diisocyanates.

Firstly, the $\mathrm{SBROH}_{5} /$ Silica composites were vulcanized under the same molar ratio of $\mathrm{NCO} / \mathrm{OH}$ (6 phr BI, $3.06 \mathrm{phr}$ BHDI, $2.99 \mathrm{phr} \mathrm{BPPDI}$, and $3.11 \mathrm{phr} \mathrm{BTDI})$. The curing curves are shown in Figure S7, and all three samples were cured effectively. As shown in Figure 9a, the tensile strengths for these three blocked diisocyanates were similar, but the modulus increased gradually in the order of B-HDI, B-PPDI, and B-TDI (Table 3). Furthermore, as shown in $\tan \delta$-T curves (Figure 9b): (1) the structure of blocked diisocyanate had little effect on $T_{\mathrm{g}}$; (2) surprisingly, $\tan \delta$ values at $60{ }^{\circ} \mathrm{C}$ for B-HDI, B-PPDI, and B-TDI were all significantly smaller than that of BI and decreased in the order of HDI, PPDI, 
and TDI. Therefore, the dynamic heat build-up was relevant to the chemical structures of diisocyanates. The $\tan \delta$ values with TDI were close to those of the SBR/S/Si69/silica and $\mathrm{SBROH}_{\mathrm{x}} /$ silica composites, as shown in Table 4 . Moreover, the resilience properties increased, and the compression set decreased, superior to the SBR/S/Si69/silica composite. It also should be noted that the higher $\tan \delta$ values at $0{ }^{\circ} \mathrm{C}(0.21)$ (Table 4$)$ suggested improved wet skid resistance in tire compound application.
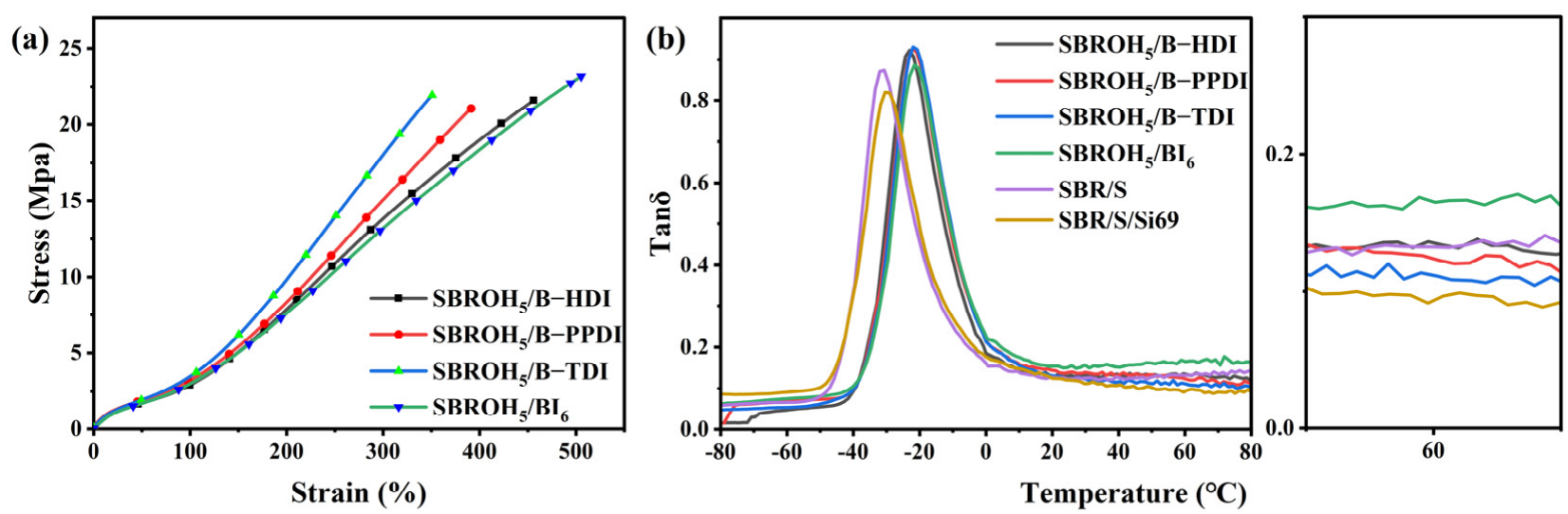

Figure 9. (a) stress - strain curves and (b) tan $\delta$-T curves of SBROHx cured by different blocked diisocyanates.

Table 3. Mechanical properties of different blocked polyisocyanates-cured $\mathrm{SBROH}_{5} \mathrm{composites}$

\begin{tabular}{|c|c|c|c|c|c|c|c|c|}
\hline Sample & $\begin{array}{c}\text { Tensile } \\
\text { Strength } \\
\text { (MPa) }\end{array}$ & $\begin{array}{l}\text { Modulus } \\
\text { at } 100 \% \\
(\mathrm{MPa})\end{array}$ & $\begin{array}{c}\text { Modulus } \\
\text { at } 300 \% \\
(\mathrm{MPa})\end{array}$ & $\begin{array}{c}\text { Elongation at } \\
\text { Break (\%) }\end{array}$ & $\begin{array}{c}\text { Shore A } \\
\text { Hardness }\end{array}$ & $\begin{array}{l}\text { Permanent } \\
\text { Set }(\%)\end{array}$ & $\begin{array}{c}\text { Resilience } \\
(\%)\end{array}$ & $\begin{array}{l}\text { Compression } \\
\text { Set }(\%)\end{array}$ \\
\hline $\mathrm{SBROH}_{5} / \mathrm{B}-\mathrm{HDI}$ & 21.6 & 2.9 & 13.8 & 456 & 77 & 8 & 52.1 & 10.3 \\
\hline $\mathrm{SBROH}_{5} / \mathrm{B}-\mathrm{PPDI}$ & 21.0 & 3.2 & 15.0 & 391 & 76 & 8 & 52.9 & 8.9 \\
\hline $\mathrm{SBROH}_{5} / \mathrm{B}-\mathrm{TDI}$ & 21.9 & 3.5 & 18.2 & 351 & 77 & 5 & 53.2 & 8.3 \\
\hline
\end{tabular}

Table 4. Tan $\delta$ at 0 and $60^{\circ} \mathrm{C}$ of composites.

\begin{tabular}{|c|c|c|}
\hline Sample & $\operatorname{Tan} \delta$ at $0^{\circ} \mathrm{C}$ & $\operatorname{Tan} \delta$ at $60{ }^{\circ} \mathrm{C}$ \\
\hline $\mathrm{SBR} / \mathrm{S}$ & 0.16 & 0.13 \\
\hline SBR/S/Si69 & 0.18 & 0.10 \\
\hline $\mathrm{SBROH}_{2} / \mathrm{BI}_{6}$ & 0.17 & 0.17 \\
\hline $\mathrm{SBROH}_{5} / \mathrm{BI}_{6}$ & 0.22 & 0.16 \\
\hline $\mathrm{SBROH}_{7} / \mathrm{BI}_{6}$ & 0.41 & 0.16 \\
\hline $\mathrm{SBROH}_{5} / \mathrm{B}-\mathrm{HDI}$ & 0.19 & 0.13 \\
\hline $\mathrm{SBROH}_{5} / \mathrm{B}-\mathrm{PPDI}$ & 0.21 & 0.12 \\
\hline $\mathrm{SBROH}_{5} / \mathrm{B}-\mathrm{TDI}$ & 0.21 & 0.11 \\
\hline
\end{tabular}

\section{Conclusions}

In summary, high crosslinking efficiency can be achieved without the introduction of other toxic activators and accelerants via sulfurization chemistry based on the reaction of hydroxyl groups with blocked polyisocyanates. In addition, the hydroxyl groups in rubber chains promoted the dispersion of silica filler. A good dispersion of silica was attained even without the usage of the silane coupling agent. The mechanical properties and crosslinking density of the samples can be readily adjusted by varying the content of hydroxyl groups and the amount of blocked polyisocyanates. Compared to the sulphurcured counterpart of the SBR/S/Si69/silica composite with a similar crosslinking density, the blocked polyisocyanates-cured $\mathrm{SBROH}_{5}$ / silica composite exhibited a higher tensile modulus. In addition, the dynamic heat build-up was affected by the distance between the two NCO groups in the diisocyanate. The $\mathrm{SBROH}_{5} / \mathrm{B}-\mathrm{TDI} /$ silica composite showed superior resilience properties and compression set, as well as a low $\tan \delta$ value at $0{ }^{\circ} \mathrm{C}$, which was very close to that of the SBR/S/Si69/silica composite. Overall, this work provides a 
new and efficient pathway to fabricate rubbers with novel structures and high mechanical and dynamic heat build-up properties. Many other properties and the applications for this strategy are currently being explored in our laboratory.

Supplementary Materials: The following supporting information can be downloaded at https: / / www.mdpi.com/article/10.3390/polym14030461/s1: Crosslinking density; Figure S1: Evolution of FTIR spectra of $\mathrm{BROH}_{\mathrm{x}}$ with increasing $\mathrm{mCPBA}$ and $\mathrm{HCl}$ dose; Figure S2: The molecular weight distribution (MWD) of $\mathrm{BROH}_{x}$; Figure S3: Evolution of FTIR spectra of $\mathrm{SBROH}_{x}$; Figure S4: ${ }^{1} \mathrm{H}$ NMR spectra of $\mathrm{SBROH}_{5}$; Figure S5: RPA curves of $\mathrm{BROH}_{\mathrm{x}}$ cured by 6 phr BI; Figure S6: Evolution of FTIR spectra of TDI and blocked TDI; Figure S7: Curing curves of $\mathrm{SBROH}_{5}$ cured by different blocked diisocyanates; Table S1: Degree of hydroxylation under different conditions; Table S2: Molecular weight distribution of BR after hydroxylation; Table S3: Molecular weight distribution of SBR after hydroxylation.

Author Contributions: L.G.: investigation, methodology, formal analysis, Writing —original draft; Q.L.: conceptualization, writing-review and editing. All authors have read and agreed to the published version of the manuscript.

Funding: This research was funded by the Scientific Research Foundation from Qingdao University of Science \& Technology.

Institutional Review Board Statement: Not applicable.

Informed Consent Statement: Not applicable.

Data Availability Statement: The data presented in this study are available on request from the corresponding author.

Conflicts of Interest: The authors declare no conflict of interest.

\section{References}

1. Ikeda, Y.; Higashitani, N.; Hijikata, K.; Kokubo, Y.; Morita, Y.; Shibayama, M.; Osaka, N.; Suzuki, T.; Endo, H.; Kohjiya, S. Vulcanization: New focus on a traditional technology by small-angle neutron scattering. Macromolecules 2009, 42, $2741-2748$. [CrossRef]

2. Kruželák, J.; Sýkora, R.; Hudec, I. Sulphur and peroxide vulcanisation of rubber compounds-overview. Chem. Pap. 2016, 70, 1533-1555. [CrossRef]

3. Brostow, W.; Datashvili, T.; Hackenberg, K.P. Effect of different types of peroxides on properties of vulcanized EPDM+ PP blends. Polym. Compos. 2010, 31, 1678-1691. [CrossRef]

4. Chokanandsombat, Y.; Sirisinha, C. MgO and $\mathrm{ZnO}$ as reinforcing fillers in cured polychloroprene rubber. J. Appl. Polym. Sci. 2013, 128, 2533-2540. [CrossRef]

5. Dong, F.; Zhao, P.; Dou, R.; Feng, S. Amine-functionalized POSS as cross-linkers of polysiloxane containing $\gamma$-chloropropyl groups for preparing heat-curable silicone rubber. Mater. Chem. Phys. 2018, 208, 19-27. [CrossRef]

6. Tanrattanakul, V.; Kosonmetee, K.; Laokijcharoen, P. Polypropylene/natural rubber thermoplastic elastomer: Effect of phenolic resin as a vulcanizing agent on mechanical properties and morphology. J. Appl. Polym. Sci. 2009, 112, 3267-3275. [CrossRef]

7. Heideman, G.; Noordermeer, J.W.; Datta, R.N.; van Baarle, B. Effect of zinc complexes as activator for sulfur vulcanization in various rubbers. Rubber Chem. Technol. 2005, 78, 245-257. [CrossRef]

8. Heideman, G.; Noordermeer, J.W.; Datta, R.N.; van Baarle, B. Multifunctional additives as zinc-free curatives for sulfur vulcanization. Rubber Chem. Technol. 2006, 79, 561-588. [CrossRef]

9. Cheng, H.; Hu, Y.; Reinhard, M. Environmental and health impacts of artificial turf: A review. Environ. Sci. Technol. 2014, 48, 2114-2129. [CrossRef]

10. Das, A.; Wang, D.-Y.; Leuteritz, A.; Subramaniam, K.; Greenwell, H.C.; Wagenknecht, U.; Heinrich, G. Preparation of zinc oxide free, transparent rubber nanocomposites using a layered double hydroxide filler. J. Mater. Chem. 2011, 21, 7194-7200. [CrossRef]

11. Lin, T.; Zhang, X.; Tang, Z.; Guo, B. Renewable conjugated acids as curatives for high-performance rubber/silica composites. Green Chem. 2015, 17, 3301-3305. [CrossRef]

12. Cordier, P.; Tournilhac, F.; Soulié-Ziakovic, C.; Leibler, L. Self-healing and thermoreversible rubber from supramolecular assembly. Nature 2008, 451, 977-980. [CrossRef]

13. Basu, D.; Das, A.; Stöckelhuber, K.W.; Jehnichen, D.; Formanek, P.; Sarlin, E.; Vuorinen, J.; Heinrich, G. Evidence for an in situ developed polymer phase in ionic elastomers. Macromolecules 2014, 47, 3436-3450. [CrossRef]

14. Pire, M.; Norvez, S.; Iliopoulos, I.; le Rossignol, B.; Leibler, L. Dicarboxylic acids may compete with standard vulcanisation processes for crosslinking epoxidised natural rubber. Compos. Interfaces 2014, 21, 45-50. [CrossRef] 
15. Pire, M.; Lorthioir, C.; Oikonomou, E.K.; Norvez, S.; Iliopoulos, I.; le Rossignol, B.; Leibler, L. Imidazole-accelerated crosslinking of epoxidized natural rubber by dicarboxylic acids: A mechanistic investigation using NMR spectroscopy. Polym. Chem. 2012, 3, 946-953. [CrossRef]

16. Zhang, X.; Tang, Z.; Guo, B. Regulation of mechanical properties of diene rubber cured by oxa-Michael Reaction via manipulating network structure. Polymer 2018, 144, 57-64. [CrossRef]

17. Wang, D.; Tang, Z.; Liu, Y.; Guo, B. Crosslinking diene rubbers by using an inverse vulcanised co-polymer. Green Chem. 2020, 22, 7337-7342. [CrossRef]

18. Baker, C.; Barnard, D.; Porter, M. New reactions for the vulcanization of natural rubber. Rubber Chem. Technol. 1970, 43, 501-521. [CrossRef]

19. Lautenschlaeger, F.; Myhre, M. Observations on the crosslinking of natural rubber with nitrosophenols and diisocyanates. Rubber Chem. Technol. 1974, 47, 100-117. [CrossRef]

20. Kempermann, T. Sulfur-free vulcanization systems for diene rubber. Rubber Chem. Technol. 1988, 61, 422-447. [CrossRef]

21. Parker, D.K.; Colvin, H.A.; Weinstein, A.H.; Chen, S.-L. Reactively curable rubbers-I: Diene elastomers with pendant isocyanate and/or hydroxyl functionality. Rubber Chem. Technol. 1990, 63, 582-598. [CrossRef]

22. Ye, N.; Zheng, J.; Ye, X.; Xue, J.; Han, D.; Xu, H.; Wang, Z.; Zhang, L. Performance enhancement of rubber composites using VOC-Free interfacial silica coupling agent. Composites Part B 2020, 202, 108301. [CrossRef]

23. Zhang, C.; Tang, Z.; Guo, B.; Zhang, L. Concurrently improved dispersion and interfacial interaction in rubber/nanosilica composites via efficient hydrosilane functionalization. Compos. Sci. Technol. 2019, 169, 217-223. [CrossRef]

24. Marković, G.; Marinović-Cincović, M.; Jovanović, V.; Samaržija-Jovanović, S.; Budinski-Simendić, J. NR/CSM/biogenic silica rubber blend composites. Compos. Part B 2013, 55, 368-373. [CrossRef]

25. Ghoreishy, M.H.R.; Alimardani, M.; Mehrabian, R.Z.; Gangali, S.T. Modeling the hyperviscoelastic behavior of a tire tread compound reinforced by silica and carbon black. J. Appl. Polym. Sci. 2013, 128, 1725-1731. [CrossRef]

26. Yatsuyanagi, F.; Suzuki, N.; Ito, M.; Kaidou, H. Effects of secondary structure of fillers on the mechanical properties of silica filled rubber systems. Polymer 2001, 42, 9523-9529. [CrossRef]

27. Gui, Y.; Zheng, J.; Ye, X.; Han, D.; Xi, M.; Zhang, L. Preparation and performance of silica/SBR masterbatches with high silica loading by latex compounding method. Compos. Part B 2016, 85, 130-139. [CrossRef]

28. Zou, H.; Wu, S.; Shen, J. Polymer/silica nanocomposites: Preparation, characterization, properties, and applications. Chem. Rev. 2008, 108, 3893-3957. [CrossRef]

29. Toyonaga, M.; Chammingkwan, P.; Terano, M.; Taniike, T. Well-defined polypropylene/polypropylene-grafted silica nanocomposites: Roles of number and molecular weight of grafted chains on mechanistic reinforcement. Polymers 2016, 8, 300. [CrossRef] [PubMed]

30. Charness, M.E.; Simon, R.P.; Greenberg, D.A. Ethanol and the nervous system. N. Engl. J. Med. 1989, 321, 442-454. [CrossRef] [PubMed]

31. Gao, W.; Lu, J.; Song, W.; Hu, J.; Han, B. Interfacial interaction modes construction of various functional SSBR-silica towards high filler dispersion and excellent composites performances. RSC Adv. 2019, 9, 18888-18897. [CrossRef]

32. Sun, C.; Wen, S.; Ma, H.; Li, Y.; Chen, L.; Wang, Z.; Yuan, B.; Liu, L. Improvement of silica dispersion in solution polymerized styrene-butadiene rubber via introducing amino functional groups. Ind. Eng. Chem. Res. 2018, 58, 1454-1461. [CrossRef]

33. Weng, P.; Tang, Z.; Huang, J.; Wu, S.; Guo, B. Promoted dispersion of silica and interfacial strength in rubber/silica composites by grafting with oniums. J. Appl. Polym. 2019, 136, 48243. [CrossRef]

34. Peng, C.-C.; Abetz, V. A simple pathway toward quantitative modification of polybutadiene: A new approach to thermoreversible cross-linking rubber comprising supramolecular hydrogen-bonding networks. Macromolecules 2005, 38, 5575-5580. [CrossRef]

35. Yin, L.; Liu, Y.; Ke, Z.; Yin, J. Preparation of a blocked isocyanate compound and its grafting onto styrene-b-(ethylene-co-1butene)-b-styrene triblock copolymer. Eur. Polym. 2009, 45, 191-198. [CrossRef]

36. Payne, A.R. The dynamic properties of carbon black-loaded natural rubber vulcanizates. Part I. J. Appl. Polym. Sci. 1962, 6, 57-63. [CrossRef] 